\title{
Factor Analysis for the Questionnaire Investigation on the Needs at Yoshiwara Shopping Street in Fuji City
}

\author{
Daisuke Suzuki \\ Fujisan Area Management Company \\ Akane Okubo \\ NIHON University Junior College, Japan \\ Yuki Higuchi \\ Faculty of Business Administration, Setsunan University \\ Kazuhiro Takeyasu \\ College of Business Administration, Tokoha University, Japan
}

\begin{abstract}
Shopping streets at local city in Japan became old and are generally declining. In this paper, we handle the area rebirth and/or regional revitalization of shopping street. We focus on Fuji city in Japan. Four big festivals are held at Fuji city (two for Fuji Shopping Street Town and two for Yoshiwara Shopping Street Town). Many people visit these festivals including residents in that area. Therefore a questionnaire investigation to the residents and visitors is conducted during these periods in order to clarify residents and visitors' needs for the shopping street, and utilize them to the plan building of the area rebirth and/or regional revitalization of shopping street. There is a big difference between Fuji Shopping Street Town and Yoshiwara Shopping Street Town. Therefore we focus Yoshiwara Shopping Street in this paper. These are analyzed by using Factor Analysis and Cluster Analysis. These are utilized for constructing a much more effective and useful plan building. We have obtained fruitful results. To confirm the findings by utilizing the new consecutive visiting records would be the future works to be investigated.
\end{abstract}

Key Words: Fuji City, Area rebirth, Regional vitalization, festival, Factor Analysis, Cluster Analysis

\section{INTRODUCTION}

Shopping streets at local city in Japan are generally declining. It is because most of them were built in the so-called "High Growth Period (1954-1973)". Therefore they became old and area rebirth and/or regional revitalization are required everywhere.

There are many papers published concerning area rebirth or regional revitalization. Inoue (2017) has pointed out the importance of tourism promotion. Ingu et al.(2017) developed the project of shutter art to Wakkanai Chuo shopping street in Hokkaido, Japan. Ohkubo (2017) has made a questionnaire research at Jigenji shopping street in Kagoshima Prefecture, Japan and analyzed the current condition and future issues. For about tourism, many papers are presented from many aspects as follows.

Yoshida et al. designed and conducted a visitor survey on the spot, which used a questionnaire to investigate the activities of visitors to the Ueno district in Taito ward, Tokyo. Doi et al. analyzed the image of the Izu Peninsula as a tourist destination in their 2003 study 
"Questionnaire Survey on the Izu Peninsula." Kano conducted tourist behavior studies in Atami city in 2008, 2009, 2014 and in other years.

In this paper, we handle the area rebirth and/or regional revitalization of shopping street. We focus on Fuji city in Japan. Fuji city is located in Shizuoka Prefecture. Mt. Fuji is very famous all around the world and we can see its beautiful scenery from Fuji city, which is at the foot of Mt. Fuji. There are two big shopping street in Fuji city. One is Yoshiwara shopping street and another one is Fuji shopping street. They became old and building area rebirth and regional revitalization plan have started. Following investigation was conducted by the joint research group (Fuji Chamber of Commerce \& Industry, Fujisan Area Management Company, Katsumata Maruyama Architects, Kougakuin University and Tokoha University). The main project activities are as follows.

A. Investigation on the assets which are not in active use

B. Questionnaire Investigation to Entrepreneur

C. Questionnaire Investigation to the residents and visitors

After that, area rebirth and regional revitalization plan were built.

In this paper, we handle above stated C. Four big festivals are held at Fuji city. Two big festivals are held at Yoshiwara Shopping Street Town and two big festivals at Fuji Shopping Street Town. At Yoshiwara Shopping Street Town, Yoshiwara Gion Festival is carried out during June and Yoshiwara Shukuba (post-town) Festival is held during October. On the other hand, Kinoene Summer Festival is conducted during August and Kinoene Autumn Festival is performed during October at Fuji Shopping Street Town. Many people visit these festivals including residents in that area.

Therefore questionnaire investigation of $\mathrm{C}$ is conducted during these periods. Finally, we have obtained 982 sheets (Yoshiwara Shopping Street Town: 448, Fuji Shopping Street Town: 534). Basic statistical analysis, Factor Analysis and Cluster Analysis are executed based on that.

In this paper, a questionnaire investigation is executed in order to clarify residents and visitors' needs for the shopping street, and utilize them to the plan building of the area rebirth and/or regional revitalization of shopping street. There is a big difference between Fuji Shopping Street Town and Yoshiwara Shopping Street Town. Therefore we focus Yoshiwara Shopping Street in this paper. Such multivariate analysis as Factor Analysis and Cluster Analysis are executed based on that. Some interesting and instructive results were obtained.

The rest of the paper is organized as follows. Outline of questionnaire investigation is stated in section 2. In section 3, Multi Correspondence Analysis is executed which is followed by the Remarks stated in section 4.

\section{OUTLINE AND THE BASIC STATISTICAL RESULTS OF THE QUESTIONNAIRE RESEARCH Outline of the Questionnaire Research}

A questionnaire investigation to the residents and visitors is conducted during these periods in order to clarify residents and visitors' needs for the shopping street, and utilize them to the plan building of the area rebirth and/or regional revitalization of shopping street. The outline of questionnaire research is as follows. Questionnaire sheet is attached in Appendix.
(1) Scope of
investigation
: Residents and visitors who have visited four big festivals at Fuji city in Shizuoka Prefecture, Japan



(2) Period
: Yoshiwara Gion Festival: June 11,12/2016
Yoshiwara Shukuba (post-town) Festival: October 9/2016
Kinoene Summer Festival: August 6,7/2016
(3) Method
Kinoene Autumn Festival: October 15,16/2016
(4) Collection
: Local site, Dispatch sheet, Self writing
: Number of distribution 1400
Number of collection 982(collection rate 70.1\%)
Valid answer 982

\section{Basic Statistical Results}

Now, we show the main summary results by single variable.

(1) Sex (Q7)

Male 55.6\%, Female $44.4 \%$

These are exhibited in Figure 1.

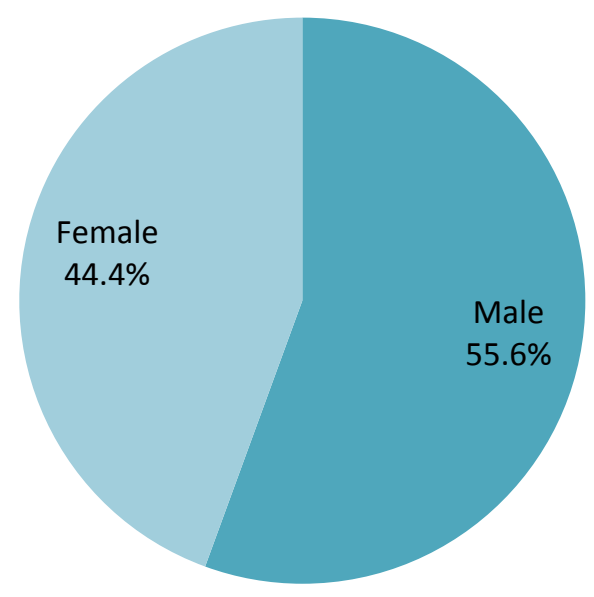

Figure 1. Sex (Q7) 
(2) Age (Q8)

$10^{\text {th }} 10.9 \%, 20^{\text {th }} 12.1 \%, 30^{\text {th }} 19.0 \%, 40^{\text {th }} 17.9 \%, 50^{\text {th }} 13.4 \%, 60^{\text {th }} 14.7 \%$, More than $7011.6 \%$ These are exhibited in Figure 2.

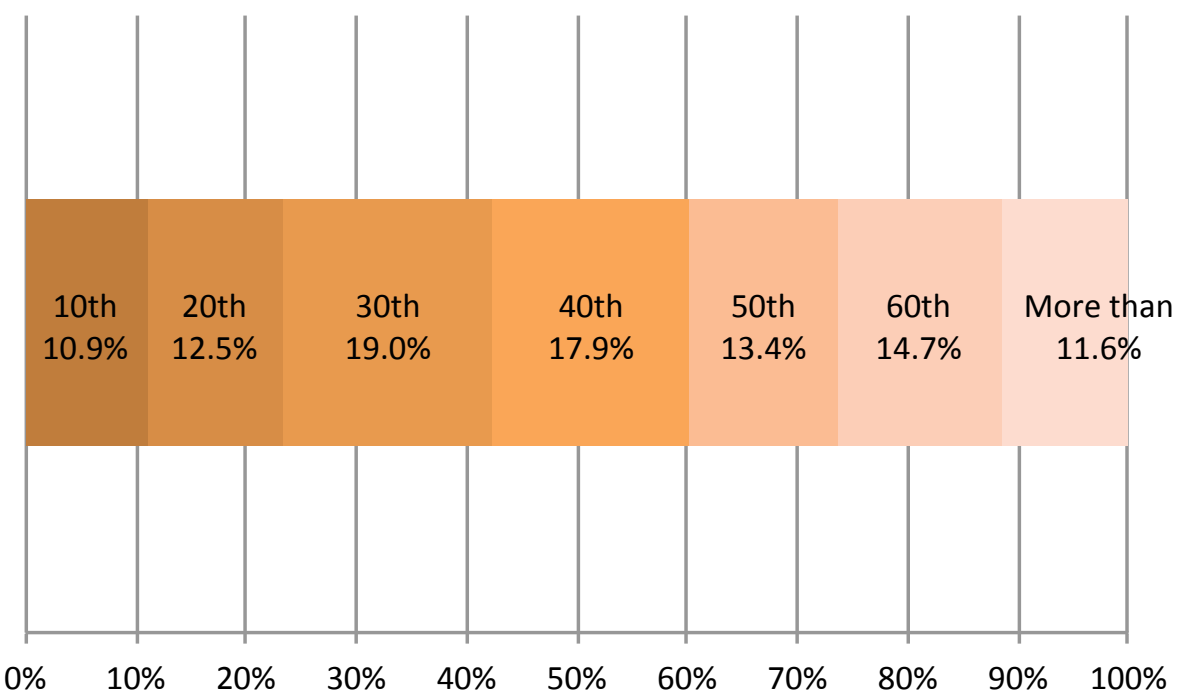

Figure 2. Age (Q8)

(3) Residence (Q9)

a. Fuji city $78.3 \%$, b. Fujinomiya city $6.9 \%$, c. Numazu city $4.5 \%$, d. Mishima city $1.3 \%$, e. Shizuoka city 2.9\%, F. Else (in Shizuoka Prefecture) 2.5\%, g. Outside of Shizuoka Prefecture $3.6 \%$

These are exhibited in Figure 3.

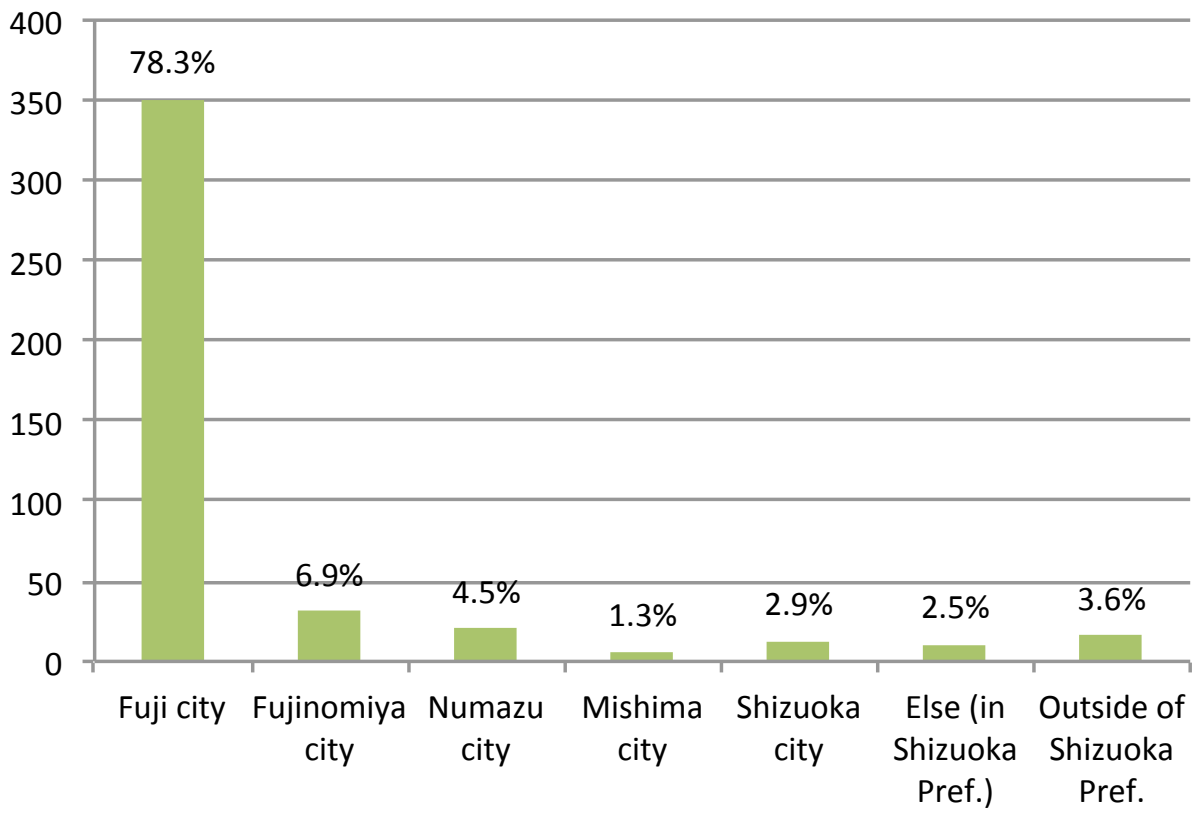

Figure 3. Residence (Q9) 
(4) How often do you come to this shopping street? (Q1)

Everyday $12.9 \%$, More than 1 time a week 15.6\%, More than 1 time a month $23.4 \%$, More than 1 time a year $37.3 \%$, First time 5.1\%, Not filled in 5.6\%

These are exhibited in Figure 4.

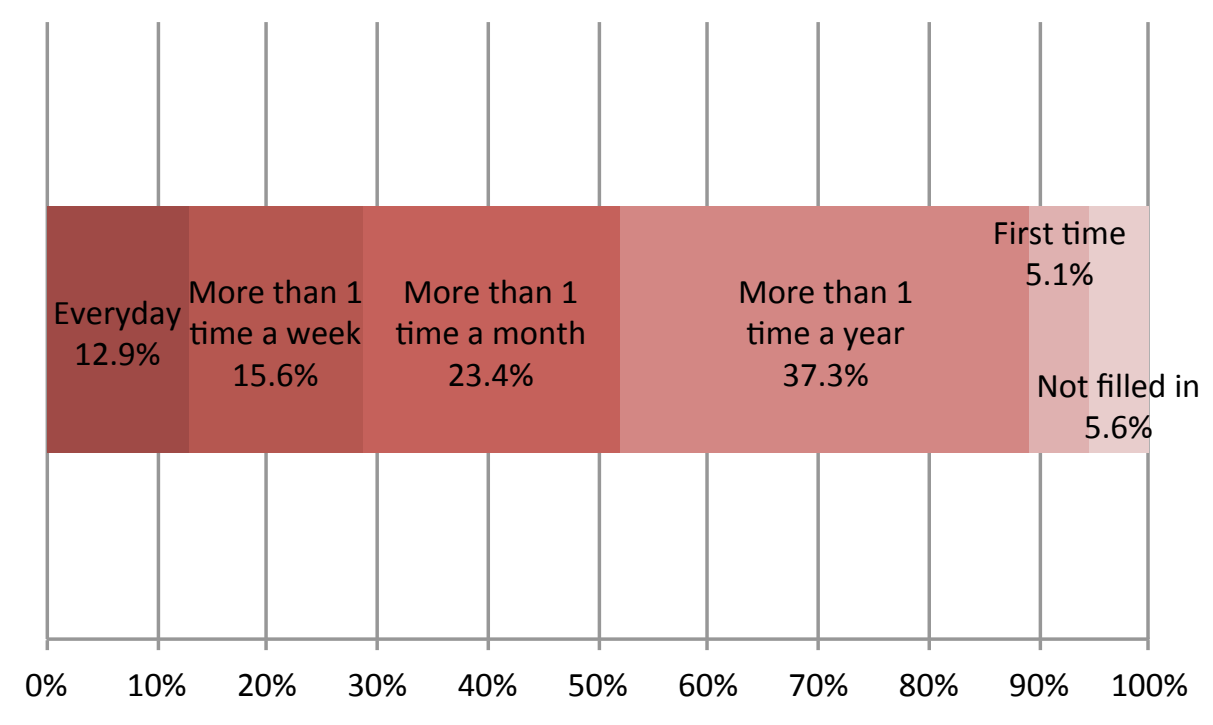

Figure 4. How often do you come to this shopping street? (Q1)

(5) What is the purpose of visiting here? (Q2)

Shopping 20.7\%, Eating and drinking 13.1\%, Business 7.5\%, Celebration, event 47.5\%,Leisure, amusement $1.5 \%$, miscellaneous $9.7 \%$

These are exhibited in Figure 5.

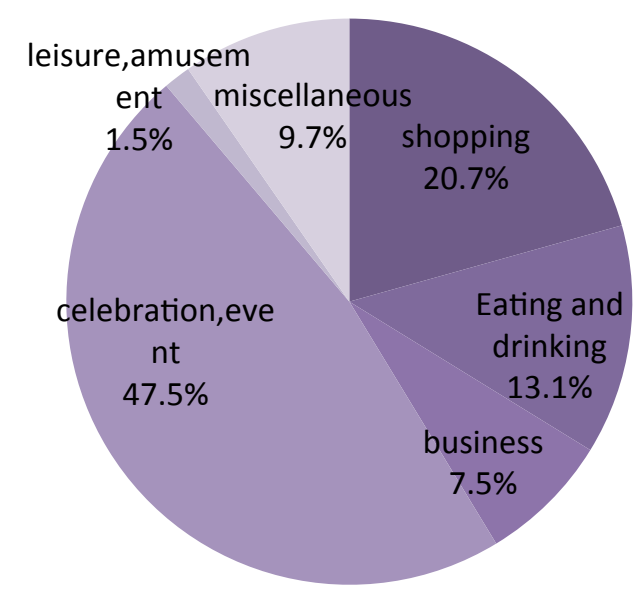

Figure 5. What is the purpose of visiting here? (Q2)

(6)How do you feel about the image of the surrounding area at this shopping street? (Q3)

Beautiful $51.9 \%$, Ugly $48.1 \%$,Of the united feeling there is $47.2 \%$,Scattered $52.8 \%$,Varied $40.0 \%$,Featureless $60.0 \%$, New $32.5 \%$,Historic $67.5 \%$,Full of nature $53.1 \%$,Urban 46.9\%,Cheerful $49.4 \%$,Gloomy 50.6\%, Individualistic $46.3 \%$,Conventional $53.7 \%$,Friendly 61.6\%,Unfriendly 38.4\%,Healed 54.2\%,Stimulated 45.8\%, Open 47.9\%,exclusive 52.1\%,Want to reside $45.1 \%$,Do not want to reside $54.9 \%$,Warm $62.6 \%$,Aloof $37.4 \%$, Fascinating 49.6\%,Not fascinating 50.4\%,Want to play $47.8 \%$,Want to examine deliberately $52.2 \%$, Lively $40.3 \%$, Calm $59.7 \%$,Atmosphere of urban $30.5 \%$,Atmosphere of rural area $69.5 \%$ 
These are exhibited in Figure 6.

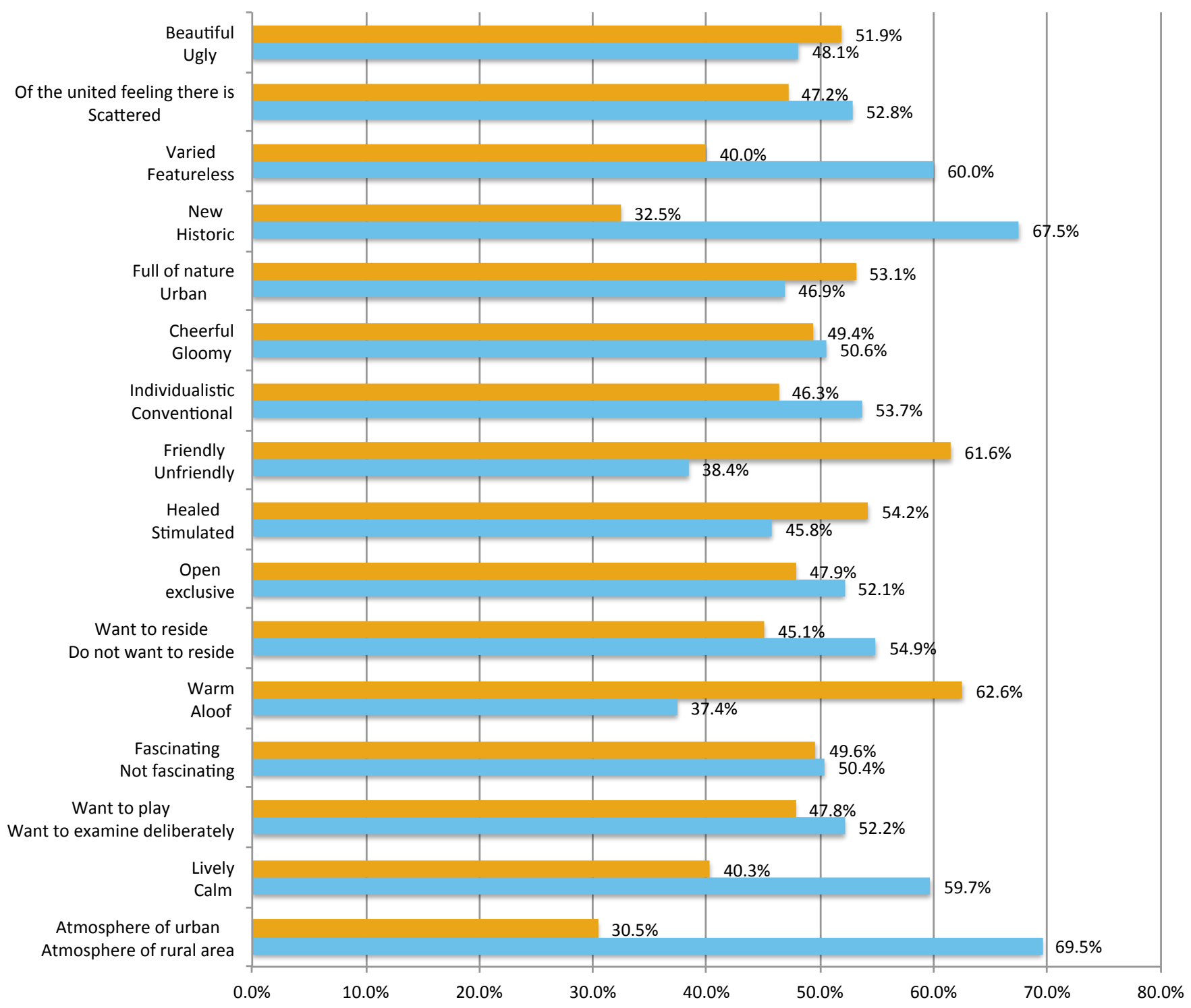

Figure 6. How do you feel about the image of the surrounding area at this shopping street? (Q3) 
(7) There are many old building at the age of nearly 50 years. Do you think we can still use them? (Q4)

Can use it $38.6 \%$, Cannot use it $33.9 \%$, Have no idea $27.5 \%$

These are exhibited in Figure 7.

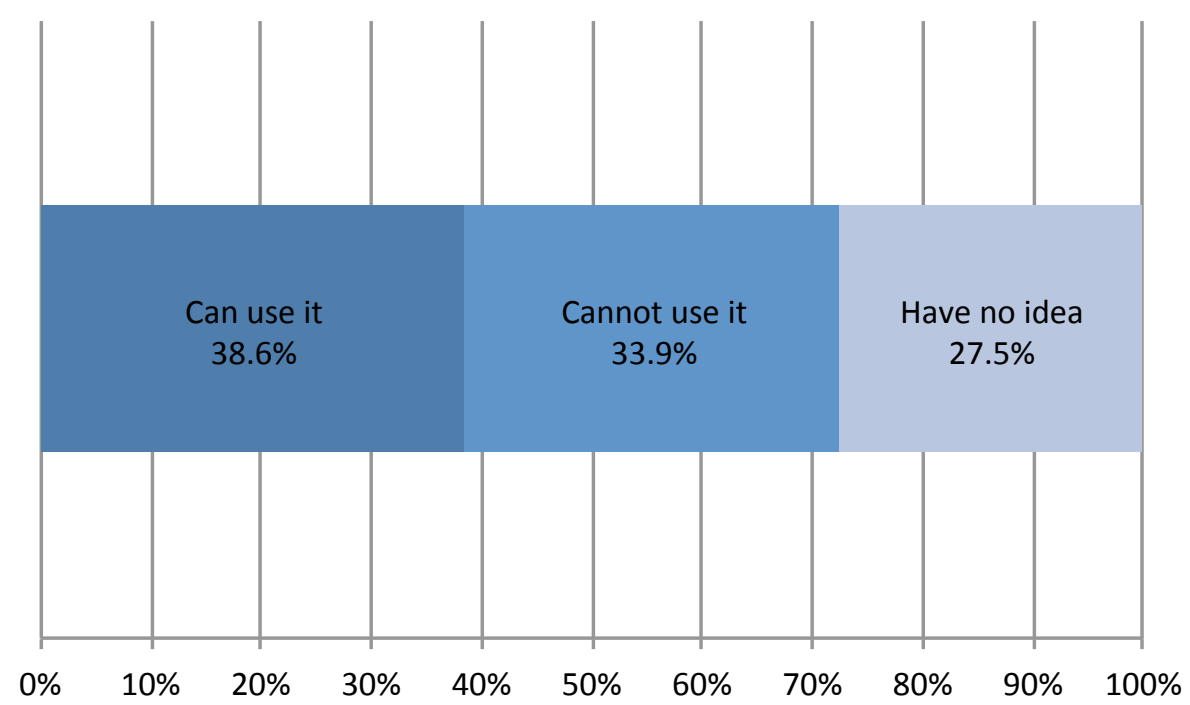

Figure 7. There are many old building at the age of nearly 50 years. Do you think we can still use them? (Q4)

\section{FACTOR ANALYSIS}

Factor Analysis is executed. As for the extraction method of the factor, "the principal axis factoring" is adopted, and as for the rolling-method, "the varimax rotation which is accompanied by the normalization of kaiser as orthogonal rotation" is adopted. Also, we confirmed the validity of the model in the KMO (Kaisel-Meyer-Olkin) specimen validity measure. When the value is more than 0.8 , it is said meritorious, more than 0.7 middling, more than 0.6, mediocre. Bartlett sphericity test is executed as well. If the score is less than 0.05 , then it is said that there is a correlation among observation variables.

Q3 "How do you feel about the image of the surrounding area at this shopping street?"

KMO measure is 0.877 and Bartlett Score is 0.000 . We can confirm a rather appropriate common factor. From the Factor Matrix after rotation (Table 1), we can extract 3 meaningful axes. Summary of factor loading value is $39.556 \%$ therefore extracted 3 factors can explain nearly $40 \%$ of the data. We can see that the first axis is the factor about "Warm and Healing" as the score for "Warm", "Friendly", "Fascinating", "Healed", "Cheerful", "Open" and "Want to reside" are high. Second axis is the factor about "Varied and Urbane" as the score for "New", "Varied", "Of the united feeling there is", "Lively", "Atmosphere of urban" and "Want to play" are high. Third axis is the factor about "Countryside Beauty" as the score for "Individualistic", "Beautiful" and "Full of Nature" are high. 
Table 1. Factor Matrix after rotation

\begin{tabular}{lrrr}
\hline & \multicolumn{3}{c}{ Factor } \\
\cline { 2 - 4 } & \multicolumn{1}{c}{1} & \multicolumn{1}{c}{3} \\
\hline Warm & .732 & .023 & .108 \\
Fascinating & .655 & .355 & .040 \\
Friendly & .646 & .117 & .390 \\
Open & .498 & .283 & .108 \\
Healed & .496 & .075 & .312 \\
Cheerful & .480 & .452 & .238 \\
Want to reside & .420 & .259 & - \\
& & & .059 \\
Lively & .314 & .654 & - \\
& & & .130 \\
Atmosphere of urban & .274 & .599 & -236 \\
Varied & .084 & .542 & .255 \\
New & - & .520 & .055 \\
Of the united feeling there is & .052 & & \\
Want to play & .231 & .506 & .255 \\
& & & - \\
Beautiful & .247 & .486 & .010 \\
Individualistic & & .476 & .239 \\
Full of Nature & .353 & .475 \\
\hline
\end{tabular}


Factor plotting in factor space is exhibited in Figure 8.

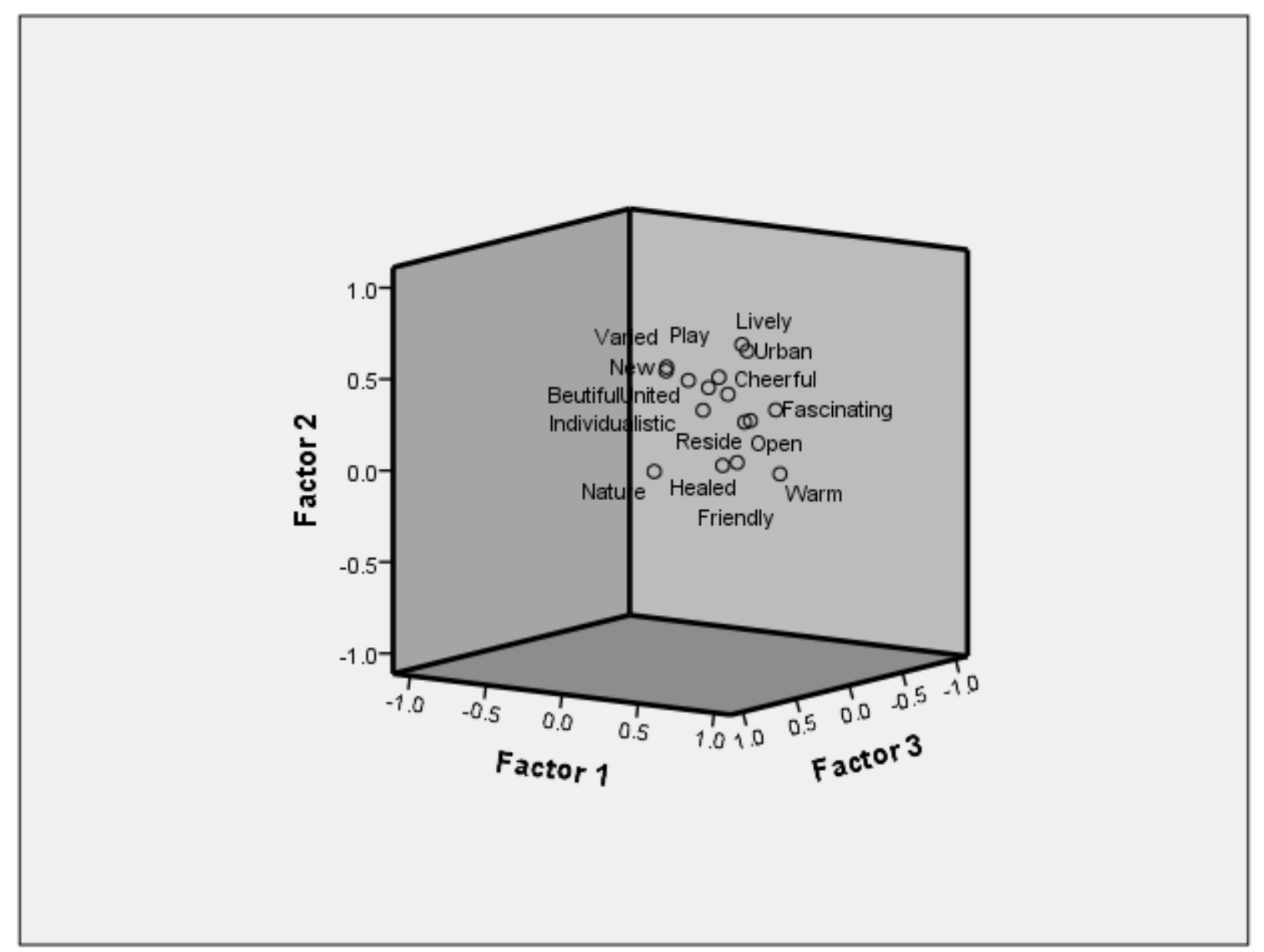

Figure 8. Factor Plotting in Factor Space

\section{CLUSTER ANALYSIS}

Cluster analysis is executed in order to confirm the relationship/closeness among items. The data used are the same with those of Factor Analysis. First of all, cluster cohesion process is exhibited in Table 2. 
Table 2. Cluster Cohesion Process

\begin{tabular}{|c|c|c|c|c|c|c|}
\hline \multirow[b]{2}{*}{ Step } & \multicolumn{2}{|c|}{ Combined Cluster } & \multicolumn{3}{|c|}{$\begin{array}{l}\text { First stage of } \\
\text { cluster }\end{array}$} & \multirow[b]{2}{*}{$\begin{array}{l}\text { Next } \\
\text { Step }\end{array}$} \\
\hline & $\begin{array}{c}\text { Cluster } \\
1\end{array}$ & $\begin{array}{c}\text { Cluster } \\
2\end{array}$ & Coefficient & $\begin{array}{c}\text { Cluster } \\
1\end{array}$ & $\begin{array}{c}\text { Cluster } \\
2\end{array}$ & \\
\hline 1 & 1 & 6 & 275.000 & 0 & 0 & 4 \\
\hline 2 & 8 & 11 & 554.000 & 0 & 0 & 13 \\
\hline 3 & 9 & 12 & 872.500 & 0 & 0 & 7 \\
\hline 4 & 1 & 2 & 1208.833 & 1 & 0 & 8 \\
\hline 5 & 14 & 15 & 1545.833 & 0 & 0 & 11 \\
\hline 6 & 3 & 4 & 1903.833 & 0 & 0 & 11 \\
\hline 7 & 9 & 10 & 2280.667 & 3 & 0 & 10 \\
\hline 8 & 1 & 7 & 2687.583 & 4 & 0 & 9 \\
\hline 9 & 1 & 13 & 3105.333 & 8 & 0 & 10 \\
\hline 10 & 1 & 9 & 3561.375 & 9 & 7 & 12 \\
\hline 11 & 3 & 14 & 4029.875 & 6 & 5 & 14 \\
\hline 12 & 1 & 5 & 4550.056 & 10 & 0 & 13 \\
\hline 13 & 1 & 8 & 5165.136 & 12 & 2 & 14 \\
\hline 14 & 1 & 3 & 6374.133 & 13 & 11 & 0 \\
\hline
\end{tabular}


Distance is calculated by using Euclidean square distance. Dendrogram by Ward method is exhibited in Figure 9.

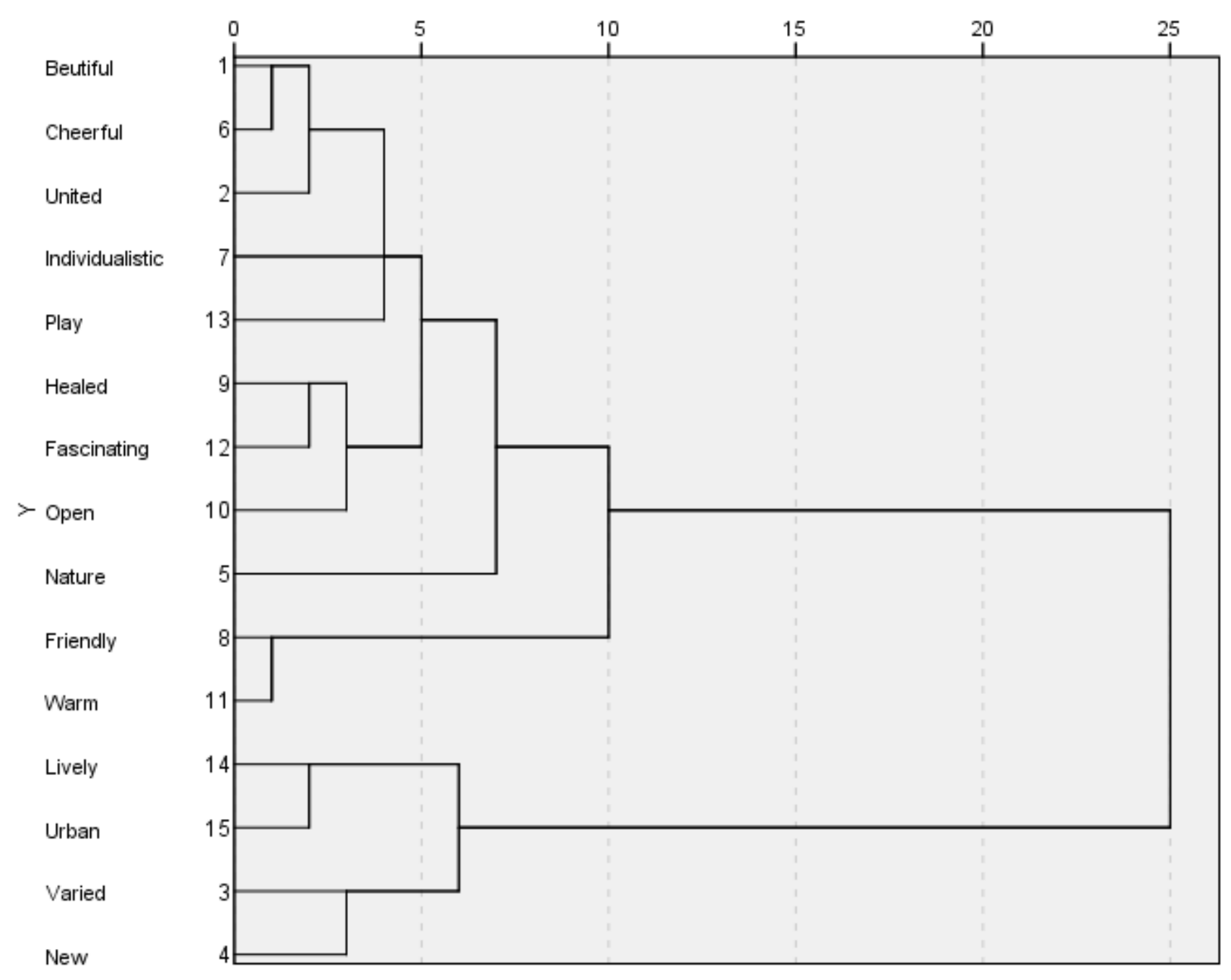

Figure 9. Dendrogram by Ward method

Watching carefully in detail, we could find that the results of Cluster Analysis correspond to those of the Factor Analysis. From the top to the bottom of the Dendrogram, we can observe the following results.

$\begin{array}{lc}\text { /Beautiful } & : \text { Factor 3 } \\ \text { /Cheerful } & : \text { Factor 1 } \\ \text { /Of the united feeling there is } & : \text { Factor 2 } \\ \text { /Individualistic } & : \text { Factor 3 } \\ \text { /Want to play } & : \text { Factor 2 } \\ \text { /Healed } \sim \text { Open } & : \text { Factor 1 } \\ \text { /Full of Nature } & : \text { Factor 3 } \\ \text { /Friendly } \sim \text { Warm } & : \text { Factor 1 } \\ \text { /Lively } \sim \text { New } & : \text { Factor 2 }\end{array}$

These are the very clear correspondence. 
Generally, Factor Analysis and Cluster Analysis are not used at the same time so far, because the method and the objective of using it is quite different. But we have obtained fruitful results as stated above. This relationship should be examined in various cases.

\section{CONCLUSION}

Shopping streets at local city in Japan became old and are generally declining. In this paper, we handle the area rebirth and/or regional revitalization of shopping street. We focus on Fuji city in Japan. Four big festivals are held at Fuji city(two for Fuji Shopping Street Town and two for Yoshiwara Shopping Street Town). Many people visit these festivals including residents in that area. There is a big difference between Fuji Shopping Street Town and Yoshiwara Shopping Street Town.

Therefore we focus Yoshiwara Shopping Street in this paper. A questionnaire investigation to the residents and visitors is conducted during these periods in order to clarify residents and visitors' needs for the shopping street, and utilize them to the plan building of the area rebirth and/or regional revitalization of shopping street. These are analyzed by using Factor Analysis and Cluster Analysis.

The results for Factor Analysis are as follows. From the Factor Matrix after rotation, we can extract 3 meaningful axes. Summary of factor loading value is $39.556 \%$ therefore extracted 3 factors can explain nearly $40 \%$ of the data. We can see that the first axis is the factor about "Warm and Healing" as the score for "Warm", "Friendly", "Fascinating", "Healed", "Cheerful", "Open" and "Want to reside" are high. Second axis is the factor about "Varied and Urbane" as the score for "New", "Varied", "Of the united feeling there is", "Lively", "Atmosphere of urban" and "Want to play" are high. Third axis is the factor about "Countryside Beauty" as the score for "Individualistic", "Beautiful" and "Full of Nature" are high.

The results for Cluster Analysis are as follows. We could find that the results of Cluster Analysis correspond to those of the Factor Analysis. From the top to the bottom of the Dendrogram, we can observe the following results.

/Beautiful
/Cheerful
/Of the united feeling there is
/Individualistic
/Want to play
/Healed Open
/Full of Nature
/Friendly Warm
/Lively New

: Factor 3

: Factor 1

: Factor 2

: Factor 3

: Factor 2

: Factor 1

: Factor 3

: Factor 1

: Factor 2

These are the very clear correspondence.

Generally, Factor Analysis and Cluster Analysis are not used at the same time so far, because the method and the objective of using it is quite different. But we have obtained fruitful results as stated above. This relationship should be examined in various cases.

These are utilized for constructing a much more effective and useful plan building.

Although it has a limitation that it is restricted in the number of research, we could obtain the fruitful results. To confirm the findings by utilizing the new consecutive visiting records would 
be the future works to be investigated.

\section{ACKNOWLEDGEMENTS}

The authors are grateful to all those who supported us for answering the questionnaire investigation.

\section{References}

Inoue, Akiko(2017) "Changes in Local Communities Brought by Municipal Mergers : From the Viewpoint of Tourism Promotion as the Main Industry", Bulletin of the Faculty of Regional Development Studies, Otemon Gakuin University, Vol.2, pp.1-32.

Ingu, Shuzo / Uemura, Miki / Uchida, Yuka / Omiya, Misa / Miura, Taiki / Hironori, Hironori(2017)"A study on the application of geothermal power generation to local revitalization in Obama Town, Unzen City: in consideration of futurability in Obama", Environmental Science Research, Nagasaki University, 20(1), pp.51-63.

Kotani, Akihiro(2017)"The implementation report of the Machi-lab shutter art project", Bulletin of Wakkanai Hokusei Gakuen University,(17),207-218.

Ohkubo, Yukio(2017) "Current status and problems in Jigenji-dori shopping area : from a consumer questionnaire", Bulletin of Local Research, Kagoshima International University, Vol.44 no.2 p.1 -15.

Shioya, Hideo "Overview and application of tourism statistics: Analysis using statistical survey on overnight travels" Journal of Economic Structures 17(1-2), 16-29, 2009 Pan Pacific Association of Input-Output Studies

Japan Tourism Agency (2015) "Research study on economic impacts of tourism in Japan 2013, p3

Yoshida, Ituki (2009) "Consideration on the Characteristic of Visitors' Activity and the Research Method for Tourist Visitors in Urban Areas"

Doi, Hideji(2009) "Evaluation of policies to build tourist destinations and statistical analysis" Nippon Hyoron Sha https://www.jnto.go.jp/eng/location/rtg/pdf/pg-410.pdf\#search='Izupeninsula'

http://www.kawazu-onsen.com/eng/

Atami city (2015) "2014 Survey of Tourist Behavior"

Kano, Michiko (2011) "Characteristic analysis of Atami tourists: Reconsideration based on data add and modify" Shizuoka Economic Research. 16 (2), p. 61-78, Shizuoka University

Takeyasu, Kazuhiro et al.(2010) “Modern Marketing”, Chuoukeizaisha Publishing 


\section{APPENDIX}

\section{Questionnaire Sheet about the Image Around the Shopping Street}

1. How often do you come to this shopping street?

a. Everyday b. ( ) times a week c. ( ) times a month d. ( ) times a year

e. miscellaneous ( )

2. What is the purpose of visiting here? (Plural answers allowed)

a. shopping b. eating and drinking c. business d. celebration、 event e. leisure, amusement

f. miscellaneous ( )

3. How do you feel about the image of the surrounding area at this shopping street?

Select the position

\begin{tabular}{|c|c|c|c|c|c|c|}
\hline Beautiful & - & - & - & - & • & Ugly \\
\hline Of the united feeling there is & - & - & - & - & - & Scattered \\
\hline $\begin{array}{ll}\text { Varied } \\
\end{array}$ & $\cdot$ & $\cdot$ & - & • & $\cdot$ & Featureless \\
\hline New & • & • & • & • & • & Historic \\
\hline Full of nature & $\cdot$ & $\cdot$ & • & $\cdot$ & $\cdot$ & Urban \\
\hline Cheerful & - & - & • & • & • & Gloomy \\
\hline Individualistic & • & • & • & - & - & Conventional \\
\hline Friendly & $\cdot$ & $\cdot$ & $\cdot$ & $\cdot$ & - & Unfriendly \\
\hline Healed & $\cdot$ & $\cdot$ & $\cdot$ & $\cdot$ & $\cdot$ & Stimulated \\
\hline Open & - & - & • & • & • & exclusive \\
\hline Want to reside & $\cdot$ & $\cdot$ & $\cdot$ & $\cdot$ & $\cdot$ & Do not want to reside \\
\hline Warm & - & - & - & - & - & Aloof \\
\hline Fascinating & • & - & • & • & - & Not fascinating \\
\hline Want to play & - & $\cdot$ & - & $\cdot$ & - & Want to examine deliberately \\
\hline Lively & $\cdot$ & $\cdot$ & • & $\cdot$ & $\cdot$ & Calm \\
\hline Atmosphere of urban & - & $\cdot$ & - & $\cdot$ & $\cdot$ & Atmosphere of rural area \\
\hline
\end{tabular}

4. There are many old building at the age of nearly 50 years. Do you think we can still use them?

a. Can use it b. Cannot use it C. Have no idea 
7. Sex

a. Male b. Female

8. Age

a.10th b.20th c.30th d.40th e.50th f.6th g. More than70

9. Residence

a. Fuji City b. Fujinomiya City c. Numazu City d. Mishima City e. Shizuoka City f. Miscellaneous in Shizuoka Prefecture g. Outside of Shizuoka Prefecture [ 